\title{
Pairing Effect pada Isotop Cr dengan Menggunakan Uniform Fixed Potential Interaction
}

\author{
Alpi Mahisha Nugraha ${ }^{1}$ dan Nurullaeli ${ }^{2}$ \\ 1,2 Program Studi Informatika, Universitas Indraprasta PGRI Jakarta \\ Jl. Nangka No.58c, Tanjung Barat, Jakarta Selatan, DKI Jakarta \\ Email : alpi.mahisha@gmail.com
}

\begin{abstract}
Pairing is collective phenomenon caused by fermions as neutron and proton collected in nuclei, this phenomenon can be found in the formation of isotopes such as the Cr-isotopes. Pairing has an impact on the amount of nuclear binding energy. Like as social being uniquely, fermions will have a strong relationship when collected in nuclei isotopes. Their binding energy will increase when the nuclei have a paired of even-even number neutron or proton. One of the most powerful approaches in explaining the pairing effect is the Bardeen-Cooper-Srhrieffer approximation (BCS-Approximation), which is forms the basis of the theory superfluidity phenomenon in nucleiIn BCS-Approximation requires an interaction potential matrix that describes the neutron interactions between energy levels. We used uniform fixed potential energy $0.5 \mathrm{MeV}, 0.1 \mathrm{MeV}$, and $0.01 \mathrm{MeV}$ which is will be an option in this approach to calculate the total binding energy in Cr-isotopes.
\end{abstract}

Keywords: Pairing effect, BCS-Approximation, Cr-isotopes, Uniform Fixed Potential Interaction

\begin{abstract}
Abstrak: Pairing merupakan fenomena keloktif dari beberapa fermion yang berkumpul, fenomena ini dapat ditemukan pada pembentukan isotop seperti isotop Cr. Pairing atau pasangan akan berdampak pada besar energi ikat inti atom, seperti halnya makhluk sosial yang akan meemliki hubungan yang kuat ketika berkumpul, isotop suatu nuklida juga akan mengalami peningkatan energi ikat ketika jumlah partikel semakin banyak dan berjumlah genap atau berpasangan. Salah satu pendekatan yang sangat powerfull dalam menjelaskan pairing effect tersebut adalah pedekatan Bardeen, Cooper, dan Schrieffer yang dikenal dengan BCS Approximation, yang menjadi dasar teori dari fenomena superfluidity. Penggunaan pendekatan ini memerlukan matriks potensial interaksi yang menggambarkan interaksi neutron antar level energi, penggunaan Uniform Fixed Potential Interaction yang bernilai $0.5 \mathrm{MeV}, 0.1$ $\mathrm{MeV}$, dan $0.01 \mathrm{MeV}$ menjadi salah satu pilihan dalam pendekatan ini untuk menghitung energi ikat total inti isotop $\mathrm{Cr}$.
\end{abstract}

Kata kunci: Pairing effect, BCS approximation, Isotop Cr, Uniform Fixed Potential Interaction

\section{PENDAHULUAN}

Inti atom isotop merupakan inti atom yang memiliki jumlah proton tetap namun mengalami penambahan jumlah neutron baik terbentuk secara alamiah atau pun buatan. Salah satu isotop yang terbentuk adalah isotop pada nuklida $\mathrm{Cr}$, keadaan alamiah atau normal dari isotop $\mathrm{Cr}$ yang stabil dan melimpah adalah nuklida $\mathrm{Cr}_{24}^{52}$ yang mencapai kandungan hampir $84 \%$ berdasarkan hasil laboratorium, salah satu laboratorium yang melakukan eksperimen terhadap isotop $\mathrm{Cr}$ adalah KAERI atau Korea Atomic Energy Research Institute. Isotop Cr merupakan isotop yang terletak diantara inti atom ringan dan inti atom sedang, keadaan inilah yang akan membuat isotop Cr menunjukkan fenomena yang menarik antara lain adalah fenomena pairing.

Fenomena pairing merupakan perilaku fermion yang bersifat kolektif yang akan berdampak pada besar energi ikat inti atom, pendekatan fundamental dari fenomena ini dipelopori oleh Bardeen, Coper, dan Schrieffer yang dikenal dengan BCS Approximation pada tahun 1957. Mulanya, pendekatan ini diaplikasikan pada zat padat untuk menjelaskan fenomena 
superkonduktivitas pada logam. Namun seiring dengan perkembangan zaman, ternyata teori ini dapat digunakan untuk menyelesaikan permasalahan pasangan pada partikel fermion apa saja, termasuk untuk neutron maupun proton pada inti atom.

Fenomena pairing dapat ditemukan pada banyak isotop, seperti yang telah ditelaah pada isotop Sn (Nugraha, 2017), isotop Zr (Urban, Varley, \& Schulz, 1995), isotop Pr (Li et al., 2002) dan lainnya. Banyaknya laboratorium yang menyediakan data dari beberapa isotop itulah yang menjadi motivasi penelitian struktur nuklir seperti pairing effect masih tetap berlangung. Bahkan beberapa peneliti yang mengaitkan fenomena pairing merupakan fenomena anti-halo sebagai serangkaian fenomena menarik yang terjadi di dalam inti atom (Bennaceur, Dobaczewski, \& Ploszajczak, 2000). Tidak hanya itu, bahkan fenomena pairing dapat ditemukan untuk fermion yang berbeda yakni proton-neutron untuk $\mathrm{N}>\mathrm{Z}$ meskipun bernilai kecil namun tidak dapat diabaikan (Civitarese \& Reboiro, 1997). Disisi lain fenomena ini juga yang membuat inti atom terdeformasi (Šimkovic, Moustakidis, Pacearescu, \& Faessler, 2003), fenomena pairing merupakan fenomena yang bertanggung jawab dalam menggambarkan bentuk interaksi fermion di dalam inti atom.

Pendekatan BCS mempersentasikan bagaimana fungsi gelombang dan tingkat energi tertentu dalam pemodelan kulit inti dengan memperhitungkan dampak fenomena pairing, sebagai faktor yang mempengaruhi perubahan energi total sistem menjadi lebih besar. Pendekatan ini menggambarkan fenomena interaksi pairing yang muncul akibat adanya interaksi antara dua partikel pada keadaan waktu yang saling konjugat (s, $\left.\mathrm{s}^{\prime}\right)$. Hubungan antara partikel yang satu dengan partikel lain digambarkan oleh matriks interaksi $V_{S S^{\prime}}$ yang menyatakan perubahan keadaan akibat interaksi yang semula berada pada $\left(s^{\prime}, \hat{s}^{\prime}\right)$ dan berakhir di keadaan $(s, \hat{\mathrm{s}})$, dengan bentuk persamaan Hamiltonian berupa :

$$
H=\sum_{s} \varepsilon_{s} n_{s}+\sum_{s s^{\prime}>0} V_{s s^{\prime}} p_{s}^{*} p_{s^{\prime}}
$$

besar energi pun menjadi

$$
E=\langle B C S|H| B C S\rangle=2 \sum_{s>0} \varepsilon_{s}^{0} v_{s}^{2}+\sum_{s s^{\prime}>0} V_{s S^{\prime}} u_{s} v_{s} u_{s^{\prime}} v_{S^{\prime}}+\sum_{s>0} V_{s S^{\prime}} v_{s}^{2}
$$

dengan $p_{s}^{*}, p_{s}$ merupakan operator yang menggambarkan pembentukan dan pemusnahan partikel. Berdasarkan penurunan persamaan energi gap atau perbedaan energi yang diakibatkan adanya pairing effect menurut pendekatan BCS diperoleh celah pairing tiap level $\Delta_{s}$, yaitu : $\Delta_{S}=\frac{1}{2} \sum_{S^{\prime}>0} \frac{\Delta_{S^{\prime}}}{\varepsilon_{S^{\prime}}} V_{S S^{\prime}}$

Penggunaan BCS Approximation memerlukan matrik potensial interaksi (Vss') yang menggambarkan interkasi yang terjadi antar level neutron. Pada isotop Sn biasanya menggunakan matriks interaksi berukuran $5 \times 5$ yang menggambarkan adanya lima level energi pada isotop Sn setelah keadaan closed shell-nya pada nuklida $S n_{50}^{100}$. Adapun matriks interaksi yang digunakan pada isotop Sn (Sumaryada, 2007) adalah sebagai berikut:

$$
\mathrm{V}_{S S^{\prime}}=\left[\begin{array}{ccccc}
-1.4738 & -0.6955 & -0.6713 & -0.3162 & 1.3052 \\
-0.6955 & -0.8843 & -1.0428 & -0.4368 & 1.0027 \\
-0.6713 & -1.0428 & -0.5160 & -0.4503 & 0.5128 \\
-0.3162 & -0.4368 & -0.4503 & -0.8466 & 0.3700 \\
1.3052 & 1.0027 & 0.5128 & 0.3700 & -1.2305
\end{array}\right]
$$

Sama halnya dengan isotop Sn, isotop Cr menggunakan pendekatan lima level energi dalam pembentukan isotopnya setelah melewati keadaan closed shell-nya pada nuklida $\mathrm{Cr}_{24}^{52}$. Meskipun dengan jumlah level energi yang sama, namun memiliki nilai yang berbeda yaitu energi level $2 \mathrm{p}_{3 / 2}, 1 \mathrm{f}_{5 / 2}, 2 \mathrm{p}_{1 / 2}, 3 \mathrm{~s}_{1 / 2}$, dan $3 \mathrm{p}_{3 / 2}$. dengan besar single energi berturut-turut -8.290 , 7.646, -7.116, -2.368, dan -2.111. 
Tujuan dari penelitian ini untuk mengetahui pairing effect pada isotop $\mathrm{Cr}$ dengan menggunakan uniform fixed potential interaction, menganalisis perhitungan properti isotop $\mathrm{Cr}$ seperti energi ikat menggunakan model uniform fixed potential interaction. dan menganalisis akurasi dan presisi model uniform fixed potential interaction dalam isotop $\mathrm{Cr}$.

\section{METODE PENELITIAN}

Pendekatan BCS berupa persamaan (1), persamaan (2) dan persamaan (3) menjadi pendekatan fundamental dalam menganalisa fenomena pairing di dalam isotop Cr. Pendekatan tersebut akan diselesaikan secara analitik dan akan diteruskan dengan metode numerik untuk menentukan energi ikat isotop $\mathrm{Cr}$ yang terbentuk dengan bantuan program MATLAB. Besaran yang dihasilkan adalah besaran yang dapat mempengaruhi properti Isotop $\mathrm{Cr}$ terutama mengenai pairing effect pada inti atom.

Matriks yang akan digunakan adalah Uniform Fixed Potential Interaction yang bernilai 0.5 , 0.1 dan 0.05 dala satuan MeV. Besar Fixed Potential Interaction ini berdasarkan analisa perhitungan yang dilakukan berdasarkan ketepatan nilai energi relatif terhadap nuklida $\mathrm{Cr}_{24}^{52}$ pada eksperimen. Penggunaan model lima level energi pada isotop $\mathrm{Cr}$ membuat perhitungan properti isotop akan dapat dilakukan hingga isotop $\mathrm{Cr}_{24}^{70}$ dimana data hasil eksperimen yang telah tersedia di KAERI mencapai isotop $\mathrm{Cr}_{24}^{68}$. Artinya kelebihan penggunaan pemodelan level ini adalah dapat memprediksi besar energi ikat yang terbentuk pada isotop $\mathrm{Cr}_{24}^{70}$.

Tahap terakhir dari metode penelitian adalah menganalisis data yang dihasilkan program Matlab dalam menghitung energi ikat sebagai properti dari isotop $\mathrm{Cr}$ dan membandingkan tingkat akurasi dan presisi dengan data eksperimen yang telah dilakukan oleh Korea Atomic Energy Research Institute (KAERI), laboratorium yang melakukan eksperiman mengenai pembentukan isotop $\mathrm{Cr}$. Hasil eksperimen berupa properti dari isotop $\mathrm{Cr}$ akan digunakan sebagai referensi tingkat akurasi dan presisi. Data yang akan diambil berupa energi ikat yang dibutuhkan untuk membentuk isotop $\mathrm{Cr}$ dari $\mathrm{Cr}_{24}^{52}$ sampai dengan $\mathrm{Cr}_{24}^{68}$.

\section{HASIL DAN PEMBAHASAN}

Isotop $\mathrm{Cr}$ adalah salah satu isotop inti ringan yang saat ini menjadi salah satu objek menarik untuk diteliti baik secara teoritik ataupun eksperimen. KAERI menjadi salah satu laboratorium internasional yang masih melakukan eksperimen terhadap objek isotop Cr hingga saat ini, namun hasil eksperimen yang tersedia hanya mencapai nuklida $\mathrm{Cr}_{24}^{68}$. Nilai yang dibandingkan dalam penelitian ini adalah energi ikat relatif dari isotop $\mathrm{Cr}$ terhadap keadaan closed shell-nya yakni nuklida $\mathrm{Cr}_{24}^{52}$ yang dihitung menggunakan Uniform Fixed Potential dan hasil eksperimen.

Nuklida $\mathrm{Cr}_{24}^{52}$ adalah nuklida dengan kondisi closed shell dikarenakan mempunyai jumlah neutron sebanyak 28 yang merupakan magic number. Pada teorinya, kondisi ini memungkinkan peneliti ekperimental untuk menambahkan neutron dengan jumlah banyak meskipun kestabilan inti akan menjadi tidak stabil seiring dengan besarnya jumlah neutron yang ditambahkan. Hal yang berpengaruh terhadap kestabilan inti ini salah satunya adalah fenomena pasangan atau pairing. Fenomena pairing adalah fenomena kolektif yang terjadi pada inti dengan jumlah neutron yang banyak dan berpasangan yakni berjumlah genap.

Fenomena pairing bersifat attraktif sehingga membuat energi ikat inti semakin kuat dan semakin negatif mengingat energi ikat bernilai negatif jadi semakin negatif nilai dari energi ikat mengartikan inti dengan energi ikat kuat. Adapun perbandingan hasil perhitungan antara perhitungan eksperimen dengan perhitungan menggunakan Uniform Fixed Potential terlihat pada Gambar 1. 


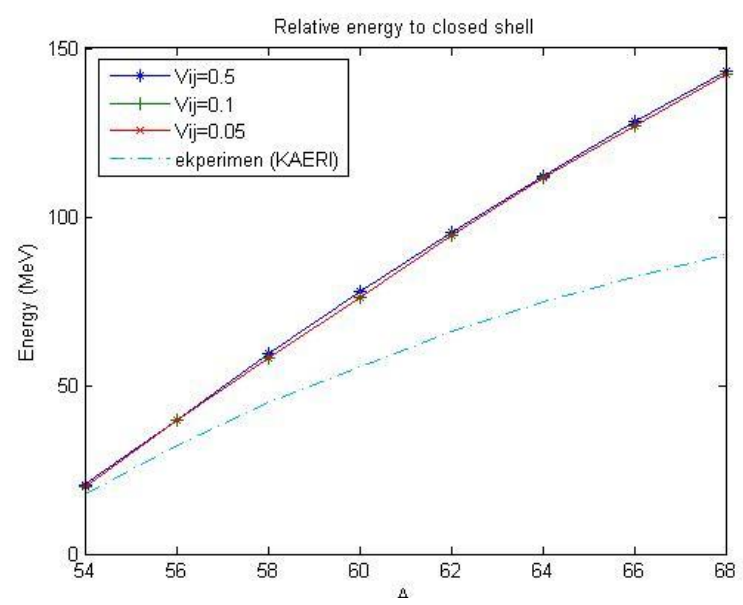

Gambar 2. Perhitungan eksperimen dan penggunaan Uniform Potential Fixed

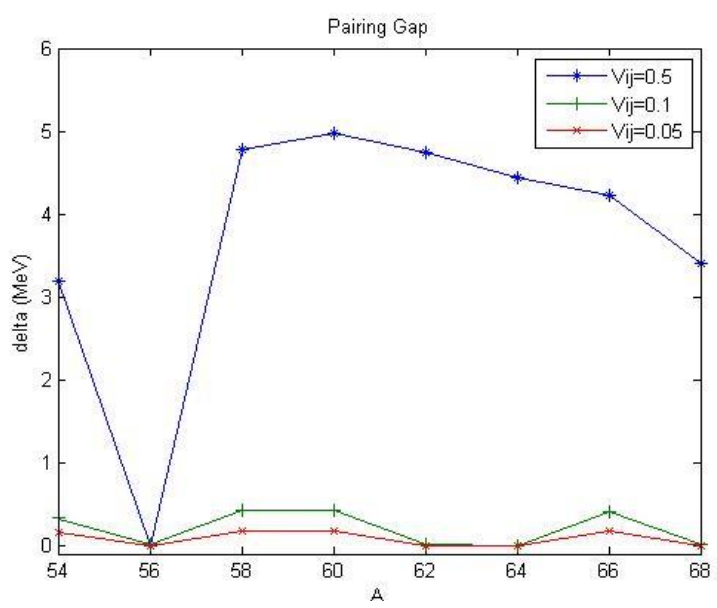

Gambar 1. Fenomena pairing pada isotop $\mathrm{Cr}$

Pada Gambar 1 memperlihatkan hasil yang semakin tidak akurat untuk isotop yang semakin besar, baik pada penggunaan $0.5 \mathrm{Mev}, 0.1 \mathrm{MeV}$ ataupun $0.01 \mathrm{MeV}$ menghasilkan nilai yang tidak jauh berbeda. Namun penggunaan Uniform Fixed Potential menjadi salah satu alternatif dalam melihat fenomena pairing pada isotop $\mathrm{Cr}$. Fenomena pairing pada isotop $\mathrm{Cr}$ dengan menggunakan lima level energi memperlihatkan bahwa neutron seolah-olah berkumpul menjadi tiga kumpulan, hal ini dikarenakan adanya level yang hampir berimpitan akibat perbedaan level energi yang kecil. Level tersebut adalah $3 \mathrm{p} 3 / 2$ dengan $3 \mathrm{~s} 1 / 2$ yang memiliki level energi berkisar $-2 \mathrm{MeV}$, kemudian $2 \mathrm{p} 1 / 2$ dengan $1 \mathrm{f} 5 / 2$ yang memiliki level energi berkisar $-7 \mathrm{MeV}$ dan kumpulan terakhir adalah level 2p3/2 yang memiliki level energi -8,290 $\mathrm{MeV}$. 
Ketiga kumpulan neutron tersebut menjadi salah satu dampak dari fenomena pairing. Terlihat pada Gambar 2 mengenai kumpulan neutron tersebut. Semakin besar Vij atau potensial interaksi semakin besar maka neutron semakin terlihat berkumpul. Potensial interaksi yang bernilai tetap atau Uniform Fixed Potential adalah besaran yang menggambarkan interaksi neutron pada level tertentu saat berinteraksi dengan level lainnya. Sehingga semakin besar nilai interaksi ini neutropn akan cenderung untuk berkumpul, pada penggunaan potensial interaksi $0.5 \mathrm{MeV}$ neutron membentuk dua kumpulan besar. Gap pairing yang dihasilkan menunjukkan adanya kumpulan gabungan antara level 3p3/2 dengan $3 \mathrm{~s} 1 / 2$ dan $2 \mathrm{p} 1 / 2,1 \mathrm{f} 5 / 2$ dengan 2p3/2.

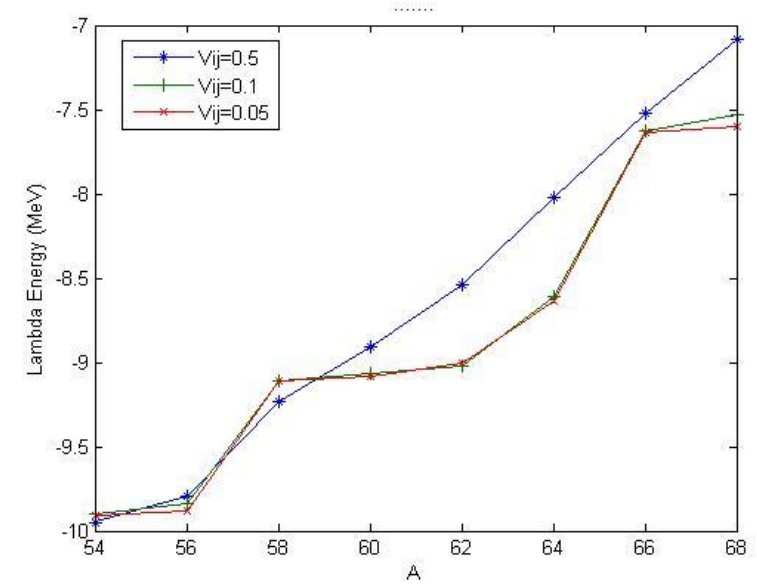

Gambar 3. Energi yang dibutuhkan untuk membentuk neutron yang ditambahkan

Lambda energy atau energi yang dibutuhkan untuk membentuk neutron pada isotop dapat terlihat pada Gambar 3. Besaran ini menunjukkan bahwa semakin banyak neutron yang ditambahkan, energi yang yang ndiperlukan untuk membentuk neutron baru semakin bernilai positif. Hal ini berarti inti isotop yang baru akan memiliki nilai energi ikat yang lebih lemah dan menunjukkan ketidak-stabilan inti isotop Cr. Pada penggunaan Uniform Fixed Potential yang bernilai $0.5 \mathrm{MeV}$, nilai lambda energy cenderung linear tidak fluktuatif seperti pada penggunaan Uniform Fixed Potential bernilai kecil seperti 0.1 dan $0.05 \mathrm{MeV}$.

Penggunaan Uniform Fixed Potential adalah step awal dari penelitian ini untuk menentukkan metode optimasi yang cocok untuk menentukan potensial interaksi yang terjadi pada isotop $\mathrm{Cr}$ bahkan isotop lainnya seperti $\mathrm{Sn}$ pada inti sedang ataupun isotop $\mathrm{Pb}$ pada inti berat, setelah penelitian tersebut dilaksanakan, peneelitian akan berlanjut pada tahap pengabungan analisis seluruh isotop yang akan dipandang dari segi sosial. Sehingga penelitian ini adalah awal dari menjadikan socialphysics menjadi salah satu alternatif melihat fenomena yang terjadi pada makhluk menggunakan sudut pandang fisika.

\section{KESIMPULAN}

Fenomena pairing pada isotop adalah salah satu fenomena yang bertanggung jawab terhadap kestabilan inti dari isotop Cr. Penggunaan Uniform Fixed Potential memang tidak memberikan hadil yang sangat akurat dengan hasil perhitungan energi ikat total yang dilakukan dalam skala laboratorium. Namun penelitian ini menjadi salah satu alternatif perhitungan dalam menghitung properties dari isotop Cr. Berdasarkan perhitungan yang telah dilakukan nilai Uniform Fixed Potential mempengaruhi nilai dari energi ikat, semakin kecil besaran ini menghasilkan perhitungan yang mendekati haisl eksperimen yakni pada nilai $0.01 \mathrm{MeV}$.

Fenomena pairing sangat terlihat pada potensial dengan nilai $0.5 \mathrm{MeV}$, pada nilai 0.1 dan $0.05 \mathrm{MeV}$ fenomena ini memang terlihat juga namun tidak sejelas pada potensial tetap bernilai 
besar. Pada nilai lambda atau energi yang diperlukan untuk membentuk partikel yang dihasilkan semakin bernilai positif seiring dengan jumlah neutron yang ditambahkan, hal ini mengartikan bahwa inti semakin tidak stabil.

\section{SARAN}

Penggunaan Uniform Fixed Potential memang tidak akan cukup memggambarkan bentuk interaksi neutron tiap level pada inti atom, neutron pada level tertentu akan memiliki nilai interaksi yang berbeda saat berinteraksi dengan level lainnya. Oleh karena itu, diperlukan metode optimasi dalam menentukan nilai pontensial interaksi agar perhitungan energi ikat yang dihasilkan sesuai dengan eksperimen, serta diperlukan juga analisis fenomena pairing pada inti isotop yang lainnya.

\section{DAFTAR PUSTAKA}

Bennaceur, K., Dobaczewski, J., \& Ploszajczak, M. (2000). Pairing anti-halo effect. Physics Letters, Section B: Nuclear, Elementary Particle and High-Energy Physics, 496(3-4), 154-160. https://doi.org/10.1016/S0370-2693(00)01292-2

Civitarese, O., \& Reboiro, M. (1997). Proton-neutron pairing effects in medium and heavy mass nuclei. Physical Review C - Nuclear Physics, 56(2), 1179-1182. https://doi.org/10.1103/PhysRevC.56.1179

Li, J., Li, J., Li, J., Ma, Z., Ma, Z., Ma, Z., ... Zhou, Y. (2002). Ground-state and pairing properties of Pr isotopes in relativistic mean-field theory. Physical Review C - Nuclear Physics, 65(6), 643051-643055. https://doi.org/10.1103/PhysRevC.65.064305

Nugraha, A. M. (2017). EFEK PAIRING PADA ISOTOP Sn ( $>82$ ) DALAM TEORI BCS MENGGUNAKAN SEMBILAN TINGKAT. 10(2), 101-110.

Šimkovic, F., Moustakidis, C. C., Pacearescu, L., \& Faessler, A. (2003). Proton-neutron pairing in the deformed BCS approach. Physical Review C-Nuclear Physics, 68(5), 8. https://doi.org/10.1103/PhysRevC.68.054319

Sumaryada, T. I. (2007). Pairing Correlations and Phase Transitions in Mesoscopic Systems. Retrieved from http://diginole.lib.fsu.edu/etd

Urban, W., Varley, B. J., \& Schulz, N. (1995). isotopes of Zr. 52(5), 2306-2309. 